\title{
ESTUDO DA PRENSAGEM DE AMENDOIM - AVALIAÇÃO DO ÓLEO BRUTO
}

\author{
S. C. GRANDE ${ }^{1}$; P. P. VALÉRIO ${ }^{1}$; V. M. D. PASA ${ }^{1}$; M. H. C. DE ANDRADE'; É. C. \\ CREN $^{1}$ \\ ${ }^{1}$ Universidade Federal de Minas Gerais (UFMG), Belo Horizonte, MG, Brasil \\ salvador.cgrande@gmail.com
}

\begin{abstract}
RESUMO - O processamento de oleaginosas tem sido uma atividade importante no setor de produção agrícola contribuindo também para a geração de renda na agricultura familiar. $\mathrm{O}$ interesse pelo óleo do amendoim, rico em ácidos insaturados, vem crescendo devido aos seus benefícios à saúde, como a redução no risco de desenvolvimento de doenças cardiovasculares. No entanto, a forma como o óleo é obtido pode interferir não só em seu rendimento, como em sua qualidade e característica nutricional. Assim, o presente trabalho avaliou a influencia de pré-tratamentos dados aos grãos (Tempo x Temperatura), antes da prensagem mecânica, no rendimento e característica dos óleos obtidos. Um planejamento fatorial $2^{2}$ foi utilizado para avaliar $\mathrm{o}$ efeito das variáveis investigadas no rendimento de óleo. $\mathrm{O}$ óleo bruto foi avaliado quanto ao perfil graxo e teor de acidez e atenderam aos padrões fixados pela Resolução RDC $n^{\circ}$ 482/1999, da ANVISA.
\end{abstract}

\section{INTRODUÇÃO}

A industrialização de oleaginosas é uma das atividades mais importantes para a sustentabilidade do agronegócio. O uso das prensas mecânicas para extração de óleo é uma tecnologia estabelecida em diversos países e revela ser um processo eficiente, associando baixo custo inicial e funcionamento simples, também sendo importante para produtores rurais de pequeno e médio porte, associações rurais e cooperativas agrícolas. Outra vantagem é que dependendo da qualidade do óleo obtido, o mesmo pode ser consumido sem necessidade de refino, como é feito com o azeite de oliva. Por outro lado, o óleo de má qualidade pode ainda ser útil para a produção de sabão e biodiesel. A extração mecânica de óleos geralmente é empregada para grãos ou sementes com elevado teor de óleo como o amendoim, o girassol, e a canola, culturas que podem ser produzidas tanto em pequena quanto em grande escala comercial (Regitano-D'arce, 2006).

Pighinelli et al. (2007), otimizaram alguns parâmetros importantes do processo de extração de óleo de amendoim em prensas do tipo expeller. Foi observado rendimentos de extração na faixa de $48,02 \%$ a 74,44 \%, para matéria prima com umidade entre 10 e $10,8 \%$ e temperatura de extração de 50 a $65^{\circ} \mathrm{C}$. Adeeko e Ajibola (1990), observaram que o aquecimento de grãos de amendoim por mais de 25 minutos em temperaturas na faixa de 70 a $160^{\circ} \mathrm{C}$, não influenciou no rendimento de extração de óleo em prensa tipo expeller. $\mathrm{O}$ aquecimento dos grãos, assim como a redução de tamanho de partículas, além de melhorar a extração do óleo também aumenta os valores de algumas propriedades físico-químicas do óleo, como o teor de ácidos graxos livres, 
índice de peróxidos e a intensidade da cor. Em processos de extração com aquecimento prolongado, acima de $40^{\circ} \mathrm{C}$, as proteínas da torta são desnaturadas com influencia sobre o teor de ácidos graxos livres (Adeeko e Ajibola, 1990, Oyinlole et al., 2004, Orhevba et al., 2013, Soetaredjo et al., 2008).

O interesse pelo óleo de amendoim vem crescendo devido sua composição rica em ácidos graxos insaturados, onde cerca de $25 \%$ são monoinsaturados (oleico) e cerca de $15 \%$ poliinsaturados, principalmente linoleico. Sua composição graxa é comparável a muitos óleos vegetais considerados nobres e benéficos a saúde como o azeite de oliva. O óleo de amendoim ainda contem compostos bioativos e vitaminas como o $\alpha$-tocoferol, importante substancia associada a poderes antioxidante. De um modo geral, o consumo de óleo de amendoim e produtos a base de amendoim está associado a redução de doenças cardiovasculares e de aterosclerose, sendo este tipo de óleo mais uma opção a ser explorada pelo mercado de produtos associado a saudabilidade (Almeida et al., 2011, Stephens et al., 2010).

Neste sentido, o objetivo do presente trabalho foi investigar a influencia dos parâmetros de pré-tratamento dos grãos de amendoim, a saber: temperatura $\left(50,60\right.$ e $\left.70^{\circ} \mathrm{C}\right)$ e tempo de exposição ao aquecimento (10, 20 e 30 minutos), no rendimento do óleo obtido por prensagem mecânica, assim como na qualidade dos óleos brutos. Para o estudo dos efeitos dos parâmetros sobre o rendimento em óleo foi utilizado um planejamento fatorial completo $2^{2}$, com 3 pontos centrais. O óleo será avaliado quanto ao perfil graxo e teor de acidez. O trabalho visa contribuir com estudos de otimização de processos para a extração de óleos de sementes e grãos com qualidade superior, inclusive otimizando a obtenção de tortas com características adequadas para gerar matéria prima para diferentes processos em indústrias alimentícia e não alimentícia.

\section{METODOLOGIA}

\subsection{Caracterização do amendoim in natura e óleo de amendoim}

Para a realização do presente trabalho, amendoim descascado foi adquirido no mercado de abastecimento de Minas Gerais (CEASA), marca Pacha, total de $50 \mathrm{Kg}$. O amendoim in natura foi caraterizados quanto sua composição centesimal, teor de umidade (Método AOCS, Ba 2b-82, AOCS, 2009), teor de óleo (Método AOCS, Ba 3-38, AOCS, 2009), teor de cinzas (Método AOCS, Ba 5a-49, AOCS, 2009) e teor de proteínas (Método AOCS, Ba 4d-90, AOCS, 2009).

Os óleos obtidos após prensagem foram caracterizados segundo seu perfil graxo, utilizando método cromatográfico segundo metodologia descrita pela AOCS (2009) (Método AOCS, Ce 1k09). Esta análise foi realizada no laboratório de ensaio de Combustíveis (LEQ - UFMG).

Os óleos ainda foram caracterizados quanto ao seu índice de acidez (IA). O índice de acidez é um parâmetro importante que reflete a qualidade do óleo. Segundo Resolução RDC 270 de 2005 (ANVISA, 2005) o teor de acidez estabelecido para óleo bruto é de $2 \%$. A determinação foi realizada seguindo metodologia descrita pelo Instituto Adolfo Lutz (IAL, 2005, Método 325/IV 2005). O índice de acidez é expresso em termos de \% de ácido oleico no óleo. 


\subsection{Planejamento dos experimentos de extração de óleo de amendoim}

Para o estudo da influencia do pré-tratamento dos grãos de amendoim antes da prensagem, no rendimento de extração de óleo e qualidade do óleo e torta obtidos, empregando aquecimento em diferentes temperaturas e tempos, um planejamento experimental fatorial completo $2^{2}$ foi empregado. Nos experimentos, dois níveis diferentes de temperatura e tempo de aquecimento dos grãos foram investigados. Três experimentos no ponto central foram adicionalmente conduzidos. Um total de 7 ensaios foram realizados, a fim de avaliar o efeito dos parâmetros investigados no rendimento (função resposta) do processo de extração de óleos. A Tabela 1 abaixo apresenta os níveis dos parâmetros investigados, assim como os experimentos conduzidos no planejamento experimental.

Tabela1 - Planejamento experimental do processo

\begin{tabular}{ccccc}
\hline & Níveis dos parâmetros & & \multicolumn{2}{c}{ Parâmetros Codificados } \\
\hline Ensaios & Tempo (min) & Temperatura $\left({ }^{\circ} \mathrm{C}\right)$ & X1 & X2 \\
\hline 1 & $(\mathrm{X} 1)$ & $(\mathrm{X} 2)$ & -1 & -1 \\
2 & 10 & 50 & 1 & -1 \\
3 & 30 & 50 & -1 & 1 \\
4 & 10 & 70 & 1 & 1 \\
5 & 30 & 70 & 0 & 0 \\
6 & 20 & 60 & 0 & 0 \\
7 & 20 & 60 & 0 & 0 \\
\hline
\end{tabular}

O estudo proposto na Tabela 1 acima, é de grande relevância para otimizar o processo de extração de óleos, pois a partir do conhecimento de como os parâmetros de operação influenciam no rendimento de óleo, os mesmos podem ser manipulados, dentro de faixas específicas, a fim de garantir condições ótimas de processo. Para a avaliação estatística do planejamento experimental o Software Statistica 7.0 foi utilizado.

Prensagem mecânica - extração de óleo de amendoim: A prensagem do óleo foi realizada empregando a miniprensa (Marca Piteba) de bancada da Figura 1, com capacidade de $5 \mathrm{~kg} / \mathrm{h}$. A prensagem ocorreu no laboratório de biocombustíveis da CETEC de Minas Gerais. Para avaliação dos parâmetros, amostras de amendoim de $500 \mathrm{~g}$ foram aquecidas em estufa (Marca FANEM) sem circulação de ar com controle de temperatura. O tempo de exposição a cada temperatura foi monitorado segundo experimentos definidos na Tabela 1 . O óleo obtido foi pesado em balança analítica (Marca Balmak, modelo Economic ELP-10) para determinação do rendimento de extração.

\section{RESULTADOS E DISCUSSÃO}

A caracterização do grão de amendoim in natura forneceu valores de teor de óleo de 48,34 \pm $0,28 \%$, teor de proteínas de $26,64 \pm 0,31 \%$, teor de cinzas de $2,16 \pm 0,04 \%$ e umidade de $6,24 \pm$ $0,58 \%$, sendo o restante da composição, $16,62 \%$ composta por fibras e carboidratos. Valores semelhantes aos encontrados acima são reportados na literatura segundo (Pighinelli et al., 2007, 
Bamgboye e Adejumo, 2011 e Rutz et al., 2011). A Tabela 2 apresenta os valores de rendimento em óleo para cada um dos experimentos do planejamento experimental.

Tabela 2 - Rendimento em óleo da prensagem mecânica sob diferentes condições de prétratamento dos grãos de amendoim

\begin{tabular}{rccc}
\hline Ensaios & $\begin{array}{c}\text { Tempo } \\
(\mathrm{min})\end{array}$ & $\begin{array}{r}\text { Temperatura } \\
\left({ }^{\circ} \mathrm{C}\right)\end{array}$ & $\begin{array}{c}\text { Rendimento em Óleo } \\
(\%)\end{array}$ \\
\hline 1 & 10 & 50 & $31,58 \pm 0,09$ \\
2 & 30 & 50 & $17,71 \pm 0,40$ \\
3 & 10 & 70 & $27,01 \pm 0,96$ \\
4 & 30 & 70 & $13,77 \pm 0,57$ \\
5 & 20 & 60 & $28,82 \pm 1,01$ \\
6 & 20 & 60 & $27,76 \pm 0,52$ \\
7 & 20 & 60 & $29,78 \pm 0,91$ \\
\hline
\end{tabular}

Observando os valores de rendimento da Tabela 2 acima, se pode notar que os resultados de rendimento de extração foram baixos, menor que $32 \%$, para a prensa utilizada. Estes resultados foram obtidos justamente pelo fato de a prensa utilizada ser de pequena escala (capacidade $5 \mathrm{~kg} / \mathrm{h}$ ) o que reflete no seu desempenho de extração. No entanto, a mesma pode ser utilizada para avaliar a influencia de parâmetros de operação no processo de extração.

Nota-se que o melhor desempenho de extração de óleo ocorreu em temperaturas de prétratamento de $50{ }^{\circ} \mathrm{C}$ por 10 minutos. O pior rendimento foi obtido quando o grão foi aquecido a 70 ${ }^{\circ} \mathrm{C}$ por 30 minutos. Avaliando o efeito dos parâmetros investigados no planejamento experimental sobre a função resposta (rendimento de óleo), nota-se que tanto a temperatura quanto o tempo de aquecimento do grão possuem efeitos negativos sobre a função resposta, ou seja, quanto menor estes parâmetros, melhor o efeito sobre o rendimento. Isso é claramente observado no modelo codificado, apresentado na Equação 1 abaixo, que descreve o efeito dos parâmetros sobre a função resposta $($ Rto $=$ rendimento de óleo $)$ ao nível de significância de 95 \%.

$$
\text { Rto }=25,22-6,78 \cdot X_{1}-2,12 . X_{2}
$$

Onde, $\mathrm{X}_{1}$ (tempo) e $\mathrm{X}_{2}$ (temperatura). O modelo codificado descrito acima obteve um coeficiente de correlação de $74 \%$, associado a um erro experimental de 3,72\%.

$\mathrm{Na}$ avaliação estatística dos efeitos da temperatura e tempo sobre o rendimento de óleo, verificou-se que ambos os efeitos contribuem negativamente com o rendimento. $\mathrm{O}$ efeito negativo do tempo é 3 vezes maior que o efeito da temperatura, demonstrando que pequenas variações no tempo de aquecimento dos grãos influencia mais o rendimento que variações na temperatura. Estas observações estão coerentes com dados da literatura onde temperaturas entre 60 e $65^{\circ} \mathrm{C}$ são apontadas como ótimas para obtenção de rendimentos de extração máximos (PighnellI et. al., 2007), da mesma forma, segundo Adeeko e Ajibola (1990) tempos de aquecimento acima de 25 minutos são indiferentes para o aumento de rendimento de extração de óleo. 
Pode-se dizer que o modelo obtido pode ser utilizado como primeiro estudo para o delineamento da otimização do processo de extração de óleos de amendoim por prensagem mecânica. A Figura 2 abaixo ilustra o comportamento da função resposta (rendimento de óleo) em função dos parâmetros de operação (temperatura e tempo de aquecimento do grão). O rendimento ótimo é obtido na faixa de temperatura de 50 a 65 e tempo de aquecimento de 10 a 20 minutos.

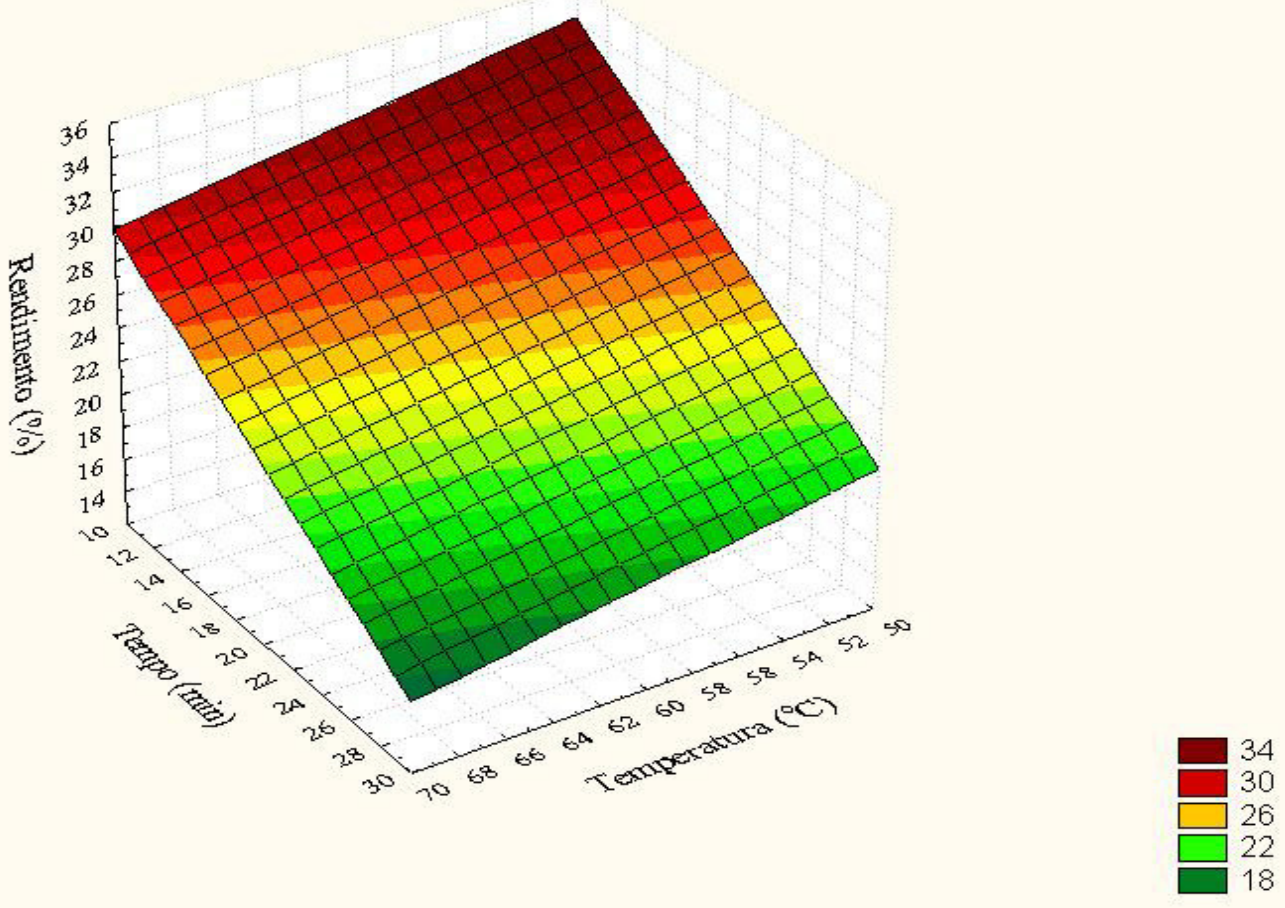

Figura 1 - Superfície de resposta do planejamento experimental

O perfil graxo e índice de acidez dos óleos bruto de amendoim também foram determinados. A Tabela 3 abaixo apresenta os valores obtidos nas diferentes condições de processo. Conforme era esperado, o perfil em ácidos graxos dos óleos obtidos não foi influenciado pelas diferentes condições estudadas no planejamento experimental. Os resultados obtidos estão de acordo com a resolução RDC 482/1999, da ANVISA (ANVISA, 2005).

Quanto ao valor de acidez, apesar de todos os óleos bruto apresentarem valores abaixo de 2 $\%$, limite estabelecido pela ANVISA para óleos bruto, nota-se que o aumento da temperatura e tempo de aquecimento do grão influencia para o aumento da acidez livre no óleo bruto obtido. Para a condição de aquecimento a $70{ }^{\circ} \mathrm{C}$ durante 10 e 30 minutos, o aumento da acidez no óleo bruto chega a ser quase $68 \%$ maior. Isso também foi identificado por outros autores como Oyinlole et. al. (2004) Tang et al. (2012). 
Tabela 3- Perfil graxo do óleo bruto de amendoim

\begin{tabular}{cccccccccccc}
\hline & & \multicolumn{9}{c}{ Tempo: 10 min } & \multicolumn{7}{c}{ Tempo: 20 min } & \multicolumn{5}{c}{ Tempo: 30 min } \\
\hline & & \multicolumn{3}{c}{ Temperatura $\left({ }^{\circ} \mathrm{C}\right)$} & \multicolumn{2}{c}{ Temperatura $\left({ }^{\circ} \mathrm{C}\right)$} & \multicolumn{4}{c}{ Temperatura $\left({ }^{\circ} \mathrm{C}\right)$} & ANVISA \\
\hline Designação & Denominação & 50 & 60 & 70 & 50 & 60 & 70 & 50 & 60 & 70 & \\
\hline C16:0 & Acido Palmitico & 11,03 & 10,6 & 10,74 & 10,71 & 11,32 & 8,5 & 12,54 & 9,41 & 11,15 & $6-16,0$ \\
C17:1 & Acido Margárico & & & & & & 0,52 & & & & $<0,1$ \\
C18:0 & Acido Esteárico & 3,76 & 3,61 & 3,95 & 2,3 & & 2,67 & 2,5 & & 2,66 & $1,3-6,5$ \\
C18:1n9c & Acido cis Oleico & 44,69 & 45,59 & 42,91 & 42,58 & 41,77 & 45,66 & 45,34 & 47,58 & 43,81 & $35-72$ \\
C18:2n6c & Acido cis Linoleico & 36,05 & 37,41 & 27,92 & 43,76 & 40,71 & 42,64 & 36,8 & 37,99 & 32,06 & $13-45$ \\
C18:2n6t & Acido trans Linoleico & & & 5,03 & & & & & & & \\
C18:3 & Acido Linolénico & & 0,89 & & & & & 1,41 & 0,96 & & $<0,3$ \\
C20:0 & Acido Araquídico & & 1,44 & 2,57 & 0,65 & & & 1,41 & 1,4 & & 1 a 3 \\
C20:5n3 & Acido Docosaeptanóico & 0,77 & & 1,57 & & 1,09 & & & & 0,95 & \\
C22:0 & Acido Behénico & 2,93 & & 4,75 & & 3,34 & & & 2,65 & 3,01 & \\
Ac. Saturados & & 18,49 & 16,1 & 22,58 & 13,66 & 14,92 & 11,17 & 16,45 & 13,46 & 16,82 & $9-20$ \\
Ac. Monoinsaturados & & 44,69 & 45,59 & 42,91 & 42,58 & 43,27 & 46,18 & 45,34 & 47,58 & 43,81 & $34-72$ \\
Ac. Poliinsaturados & & 36,82 & 38,3 & 34,52 & 43,76 & 41,8 & 42,64 & 38,21 & 38,95 & 33,01 & $12-46$ \\
Índice de Acidez (IA) \% & 0,37 & 0,43 & 0,49 & 0,53 & 0,45 & 0,67 & 0,95 & 1,34 & 1,5 & $<2$ \\
\hline
\end{tabular}

Conforme se pode notar na Tabela 3 acima, o óleo bruto de amendoim é rico em ácidos graxos mono e poli-insaturados, principalmente oleico e linoleico, ácidos graxos estes que classificam o óleo de amendoim como de boa qualidade do ponto de vista nutricional, sendo benéfico para a saúde, onde o interesse crescente pelo seu uso está voltado para a prevenção de doenças cardiovasculares, sendo comparável ao azeite de oliva, que possui entre 55 e $85 \%$ de ácido oleico e 7,5 e 21\% de ácido linoleico (Gunstone, 2002, Sousa, et al., 2013).

É válido observar ainda, que a menor acidez obtida chega ao nível de $0,37 \%$, valor este muito próximo ao estabelecido pela ANVISA, de $0,3 \%$ para óleos refinados, refletindo assim a boa qualidade do óleo bruto obtido.

\section{CONCLUSÃO}

A extração do óleo de amendoim por prensagem mecânica é influenciado por prétratamentos dados aos grãos em diferentes condições de tempo de aquecimento e temperatura. $\mathrm{O}$ presente trabalho demonstra que o tempo de aquecimento possui uma influencia maior sobre o rendimento de óleo que a temperatura. De um modo geral, ambos os parâmetros possuem efeito negativo sobre o rendimento quando seus valores são aumentados. Os parâmetros investigados demonstraram grande influencia na qualidade do óleo obtido, em termos de acidez livre, sendo que tempo e temperatura de aquecimento maiores, geram óleos bruto mais ácidos, no entanto, dentro dos limites estabelecidos pela legislação. Contudo, pode-se dizer que a investigação de parâmetros de processo de extração de óleo por prensagem mostra-se de extrema importância para o delineamento do processo a fim de obter óleos brutos com qualidade superior e características que minimizam a necessidade de refino e tratamentos drásticos do óleo, minimizando também os efeitos negativos de perdas de nutrientes dos óleos.

Agradecimentos: À CAPES e ao Departamento de Engenharia Química, da Escola de Engenharia da UFMG, pelas Bolsas concedidas e apoio na realização do presente Trabalho. 


\section{REFERÊNCIAS BIBLIOGRÁFICAS}

ADEEKO, K.A. e AJIBOLA, O. O. Processing Factors affecting Yield and Qulity of mechanically expressed groundnut Oil. Journal of Agricultural Engineering Research, n. 45, p.31-43, 1990.

ALMEIDA, B.B. DE.; CASTRO, G. S. F. DE.; JORDAO A. A. O amendoim e a saúde: Fatos e Mitos. NUTRI RP, USP RP, Projeto Aboisa, 2011.

ANVISA. RESOLUÇÃO - RDC No 482, DE 23 DE SETEMBRO DE 1999, Regulamento Técnico para Fixação de Identidade e Qualidade de Óleos e Gorduras Vegetais, 1999.

AOCS - American Oil Chemist's Society. Official methods and recommended Practices of the AOCS. Champaign: AOCS,2009.

BAMGBOYE,A.I.; ADEJUMO, O.I. Effects of processing parameters of Roselle seed on its Oil yield. Int. J.Agric \& Biol Eng. V.4, n.1, p.82-86, 2011.

GUNSTONE, F.D. Vegetable Oils in Food Technology: Composition, properties and uses. Blackwell Publishing, USA and Canada CRC, 2002.

I.A.L- Instituto Adolfo Lutz. Métodos Físico-Químicos para Análise de Alimentos - $4^{\mathrm{a}}$ Edição1 ${ }^{\mathrm{a}}$ Edição Digital.2005

ORHEVBA, B.A, CHUKWU, O. OSUNDE, Z.D. e OGWAGWU, V. Studies on the effects of pressure on yield of mechanically expressed neem kernel oil. Global journal of Engineering, design technologic, v.2 n.5, September/October, 2013.

OYINLOLe, A.; OJO, A.; ADEKOYA, L.O. Development of a laboratory model screw press for peanut oil expression. Journal of Food Engineering, n.64, p.221-227, 2004.

PIGHINELLI, A.L.M.T.;PARK, K.J.; RAUNE, A.M.; BEVILAQUA, G.; FILHO, J.A.G. Otimização de prensagem a frio de grãos de amendoim em prensas continua tipo expeller. Ciência e tecnologia de alimentos, Campinas, Suplemento n. 28, p.66-71, Dezembro 2007.

REGITANO-D'ARCE, M.A.B, Extração e refino de Óleos Vegetais. Fundamentos de Ciência e Tecnologia de Alimentos, SP-Brasil: Editora Manole, 2006.

RUTZ,J.K.;VOSS,G.B.;MACHADO,M.R.G.;RODRIGUES, R.de S. Elaboração de alimentos em barra à base de torta Residual de extração do óleo de amendoim por prensagem, B.CEPPA, Curitiba, v.29,n.2, p.173-180, Jul/Dez. 2011.

SOETAREDJO, F.E., BUNDIJANTO, G.M.; PRASETO, R.I and INDRASWATI, N. Effects of pre-treatment condition the yield and quality of neem oil obtained by mechanical pressing, ARPN Journal of Engineering and Applied Sciences, v.3, n.5, p.20-24, October, 2008.

SOUSA, L. C.; ROCHA, E. D.; ROCHA, C. P. Análises de óleos vegetais e óleo residual bruto por cromatografia gasosa visando à produção do biodiesel. Conexão ci.: r.cient. UNIFOR$M G$, Formiga,v.8,n.2, p.85-91, Jul./Dez. 2013.

STEPHENS, A. M.; DEAN, L.L; DAVIS, L J.P.; SANDERS, T.H. Peanuts, peanut oil and fat free Peanut flour Reduced in Cardiovascular Disease Risk Factors and the Development of Atherosclerosis in Syriam Golden Hamsters. JFS H: Health, Nutrition and Food , v.75, n.4, 2010.

TANG, L.; SUN, J.; ZHANG, H.C.; ZHANG, C. S.; YU, L.; NA, BI, J.; ZHU, F.; LIU, S.F.; YANG, Q.L. Evaluation of Physicochemical and Antioxidant Properties of Peanut Protein Hidrolysate. PLOS.ONE, v.7, May 2012. 